\title{
Molecular analysis of alternative transcripts of equine AXI receptor tyrosine kinase gene
}

\author{
Jeong-Woong Park', Ki-Duk Song ${ }^{2}$, Nam Young Kim³ ${ }^{3}$ Jae-Young Choi ${ }^{1}$, Seul A Hong ${ }^{1}$, Jin Hyeog Oh${ }^{1}$, \\ Si Won Kim , Jeong Hyo Lee ${ }^{4}$, Tae Sub Park ${ }^{4}$, Jin-Kyoo Kim, Jong Geun Kim ${ }^{4, *}$, and Byung-Wook Cho ${ }^{1, *}$
}

\footnotetext{
* Corresponding Authors: Jong Geun Kim Tel: +82-33-339-5728, Fax: +82-33-339-5763, E-mail: forage@snu.ac.kr

Byung-Wook Cho

Tel: +82-55-350-5515, Fax: +82-55-350-5519

E-mail: bwcho@pusan.ac.kr

${ }^{1}$ Department of Animal Science, College of Natural Resources and Life Sciences, Pusan National University, Miryang 50463, Korea

2 Department of Animal Biotechnology, Chonbuk

National, University, Jeonju 54896, Korea

${ }^{3}$ National Institute of Animal Science, Rural

Development Administration, Jeju 63242, Korea

${ }^{4}$ Graduate School of International Agricultural

Technology and Institute of Green-Bio Science and

Technology, Seoul National University, Pyeongchang 25354, Korea

${ }^{5}$ Department of Microbiology, College of Natural

Sciences, Changwon National University, Changwon 51140, Korea
}

Submitted May 25, 2017; Revised Jun 24, 2017; Accepted Jul 28, 2017
Objective: Since athletic performance is a most importance trait in horses, most research focused on physiological and physical studies of horse athletic abilities. In contrast, the molecular analysis as well as the regulatory pathway studies remain insufficient for evaluation and prediction of horse athletic abilities. In our previous study, we identified $A X L$ receptor tyrosine kinase $(A X L)$ gene which was expressed as alternative spliced isoforms in skeletal muscle during exercise. In the present study, we validated two $A X L$ alternative splicing transcripts (named as $A X L a$ for long form and $A X L b$ for short form) in equine skeletal muscle to gain insight(s) into the role of each alternative transcript during exercise.

Methods: We validated two isoforms of $A X L$ transcripts in horse tissues by reverse transcriptase polymerase chain reaction (RT-PCR), and then cloned the transcripts to confirm the alternative locus and its sequences. Additionally, we examined the expression patterns of $A X L a$ and $A X L b$ transcripts in horse tissues by quantitative RT-PCR (qRT-PCR).

Results: Both of $A X L a$ and $A X L b$ transcripts were expressed in horse skeletal muscle and the expression levels were significantly increased after exercise. The sequencing analysis showed that there was an alternative splicing event at exon 11 between $A X L a$ and $A X L b$ transcripts. 3-dimentional (3D) prediction of the alternative protein structures revealed that the structural distance of the connective region between fibronectin type 3 (FN3) and immunoglobin (Ig) domain was different between two alternative isoforms.

Conclusion: It is assumed that the expression patterns of $A X L a$ and $A X L b$ transcripts would be involved in regulation of exercise-induced stress in horse muscle possibly through an NF- $\mathrm{B}$ signaling pathway. Further study is necessary to uncover biological function(s) and significance of the alternative splicing isoforms in race horse skeletal muscle.

Keywords: Horse; AXL Receptor Tyrosine Kinase; Alternative Splicing; Athletic Performance; Muscle; RNA-Sequence

\section{INTRODUCTION}

The racing abilities such as speed are the most important economic traits in race horse and the Thoroughbred is a specific breeding strain for racing. Although many studies were focused on physical and physiological adaptations, the regulatory pathways and mechanisms of targeted genes are still remained to be uncovered in race horse [1].

In our previous study, the whole transcriptome from blood and muscle tissues before and after exercise were analyzed by RNA-sequencing. 32,361 of unigene clusters were identified and 1,305 of differentially expressed genes (DEGs) were discovered. Among these DEGs, we found an alternative splicing forms in cordon-bleu WH2 repeat protein-like 1 (COBLL1), cytoplasmic dynein 1 light intermediate chain 2 (DYNC1LI2), pleckstrin homology domain containing, family member 1 (PLEKHG1), and AXL receptor tyrosine kinase (AXL) genes [2]. 
AXL belongs to receptor tyrosine kinases (RTKs) as like as Sky (also known as Tyro-3) and Mer (also known as Eyk, Nym, and tyro12) [3], and generally RTKs are involved in cellular proliferation, survival, adhesion and cell migration [4-6]. These members of subfamily are represented by characteristic of extracellular domain. RTKs are composed of two immunoglobulin (Ig)-like domains and two fibronectin type 3 domains [7,8]. Main ligand of AXL is growth-arrest-specific gene 6 (Gas6) and the crystal structure of the AXL/Gas6 complex revealed that Gas6 initiates various cascade signalings [9-11]. AXL is activated upon paracrine or autocrine binding of Gas6, and the activated AXL is also known to be involved in cell proliferation, survival and anti-apoptosis, cell migration through the MEK-ERK, PI3K-AKT, Src, and p38MAPK signaling pathways [12-15]. Despite of many studies on $A X L$, the specific roles of $A X L$ gene on athletic abilities are still unclear. Therefore, in this study, we focused on the analysis of the $A X L$ expression analysis which was identified as one of the alternatively spliced genes during racing and exercise. We confirmed the presence of alternative splicing forms of $A X L$ transcripts in skeletal muscle tissue and examined the expression pattern of each alternative splicing form in response to exercise, and finally, estimated 3-dimentional (3D) protein structure of each alternative isoform protein.

\section{MATERIALS AND METHODS}

\section{Horse tissue sampling and RNA sequencing analysis}

All procedures were conducted by following the protocol that had been reviewed and approved by the Institutional Animal Care and Use Committee at Pusan National University (protocol numbers: PNU-2013-0417, PNU-2013-0411). Horse tissue sampling and RNA sequencing data were described in our previous study [2]. The animals performed a combination of different horse gaits which included trotting and cantering through lunging and long-reining (circular bridge lunging) as their form of exercise. Generally, racehorses are subjected to exercise for 17 to $18 \mathrm{~min}$ per day, however horses in this study followed a combined 30min exercise of trotting and cantering. Briefly, the samples were obtained from the blood and skeletal muscle samples before and 30 min after exercise. Whole transcriptome analysis was conducted by RNA sequencing and bioinformatics tools [2].

\section{Total RNA isolation}

Total RNA samples for investigation of $A X L$ transcript expression were collected from three Thoroughbreds. Skeletal muscle tissues were extracted for polymerase chain reaction (PCR) analysis. The various tissues sampled from the horses (50 to $100 \mathrm{mg}$, or $3 \mathrm{~mL}$ in the case of blood) were crushed with a mortar-pestle and mixed with $9 \mathrm{~mL}$ of red blood cell (RBC) lysis buffer (Solgent Co. Ltd., Daejeon, Korea) to remove RBC. The cells were then dissolved using $1 \mathrm{~mL}$ of TRIzol (Invitrogen, Karlsruhe, Germany), and 200 $\mu \mathrm{L}$ of chloroform was added to remove cells from the organic solvent. The mixture was then shaken for $10 \mathrm{~s}$ and left at $4^{\circ} \mathrm{C}$ for $5 \mathrm{~min}$. Centrifugal separation was carried out at $4^{\circ} \mathrm{C}$ for $15 \mathrm{~min}$, and then the supernatant was removed to a new test tube and mixed with the same amount of isopropanol. The test tube was left at $4^{\circ} \mathrm{C}$ for $15 \mathrm{~min}$ to produce RNA pellets. The isopropanol was removed by carrying out centrifugal separation at $4^{\circ} \mathrm{C}$ for $15 \mathrm{~min}$ and the sample was then sterilized with $85 \%$ ethanol and dissolved in RNase-free water. The purity of the extracted RNA was confirmed by measuring the absorbance at $230 \mathrm{~nm}$ and $260 \mathrm{~nm}$ using a spectrophotometer (ND-100, Nano Drop Technologies Inc., Wilmington, DE, USA), and only the extracted RNA with purity (optic density value at $230 \mathrm{~nm}$ divided by optic density value at $260 \mathrm{~nm}$ ) over 1.8 (found via quantitative analysis) was used. The selected RNA was stored at $-70^{\circ} \mathrm{C}$ until the experiment occurred.

\section{cDNA synthesis}

In order to synthesize cDNA, $2 \mu \mathrm{g}$ of RNA, $1 \mu \mathrm{L}$ of oligo-dT (Invitrogen, Germany), and $1 \mu \mathrm{L}$ of RNase-free water were added, the mixture was denatured at $80^{\circ} \mathrm{C}$ for $3 \mathrm{~min}$, and then the cDNA was synthesized using $4 \mu \mathrm{L}$ of $5 \times$ RT buffer, $5 \mu \mathrm{L}$ of $2 \mathrm{mM}$ deoxynucleotide (dNTP), $0.5 \mu \mathrm{L}$ of RNase inhibitor (Promega Corporation, Madison, WI, USA), and $1 \mu \mathrm{L}$ of moloney murine leukemia virus reverse transcriptase (Promega, USA).

\section{Polymerase chain reaction}

The nucleotide sequences of horse $A X L$ gene from the National Center for Biotechnology Information (http://www.ncbi.nlm.nih. gov) and the Ensembl Genome Browser (http://www.ensembl. org) were retrieved to design the primers with PRIMER3 software (http://bioinfo.ut.ee/primer3-0.4.0/). The original horse AXL transcripts were amplified by the primer pairs which were designed to detect each of alternative variants, $A X L a$-forward (5'GAG CAA GGA CAG CCA ATC CAC CAG CTG-3') and AXLareverse (5'-TGT TGG TTC AAA CAC CTC TCC-3') for AXLa, and $A X L b$-foward (5'-GCC CTG GCG CCC AGT GAG TGA-3') and $A X L b$-reverse (5'-TTC AAG GTG GCT TCA GTG GT-3') for $A X L b$, were used to specifically detect each isoform. The PCR to amplify the target genes on the CDNA was carried out under the following conditions: $1.8 \mu \mathrm{L}$ dNTP, $2 \mu \mathrm{L} 10 \times$ buffer, $0.2 \mu \mathrm{L}$ Taq, and $12 \mu \mathrm{L}$ distilled water were added to $2 \mu \mathrm{L}, 50 \mathrm{ng} / \mu \mathrm{L}$ diluted DNA and $5 \mathrm{pmol} / \mu \mathrm{L}$ diluted forward primer and reverse primer. The PCR was carried out in a total volume of $20 \mu \mathrm{L}$. The PCR procedure was: denaturation at $94^{\circ} \mathrm{C}$ for $10 \mathrm{~min}$, and a second denaturation at $94^{\circ} \mathrm{C}$ for $30 \mathrm{~s}$, followed by annealing at $58^{\circ} \mathrm{C}$ for $30 \mathrm{~s}$, and extension at $72^{\circ} \mathrm{C}$ for $30 \mathrm{~s}$. This was repeated for $40 \mathrm{cycles}$, and then a final extension was performed at $72^{\circ} \mathrm{C}$ for $10 \mathrm{~min}$. The band was confirmed on UV using a 1.5\% SeaKem LE agarose gel (Lonza, Rockland, MD, USA).

\section{Real time qPCR amplification}

To analyze the expression level of $A X L$ alternative splicing isoforms 
in muscle before and after exercise, quantitative reverse-transcription polymerase chain reaction (qRT-PCR) was conducted by using the BioRad CFX-96 machine (BioRad, Hercules, CA, USA). Each reaction was executed in a total $25 \mu \mathrm{L}$ of mixture containing $14 \mu \mathrm{L}$ of SYBR green master mix, $2 \mu \mathrm{L}$ of forward primer ( $5 \mathrm{pmol}), 2 \mu \mathrm{L}$ of reverse primer ( $5 \mathrm{pmol}), 5 \mu \mathrm{L}$ of distilled water, and $2 \mu \mathrm{L}(50 \mathrm{ng} / \mu \mathrm{L})$ of cDNA. The PCR conditions were at $94^{\circ} \mathrm{C}$ for $5 \mathrm{~min}$ of pre-denaturation step, 39 cycles of $94^{\circ} \mathrm{C}$ for $20 \mathrm{~s}, 56^{\circ} \mathrm{C}$ for $20 \mathrm{~s}$, and $72^{\circ} \mathrm{C}$ for $30 \mathrm{~s}$, and followed by $72^{\circ} \mathrm{C}$ for 10 $\mathrm{min}$ as a final step. All measurements were performed in triplicate for all specimens, and the comparative method used was the $2^{-\Delta \Delta C t}$ method [16]. The relevant expression of the target genes was calculated using glyceraldehyde-3-phosphate dehydrogenase as a normalizer.

\section{Phylogenetic analysis}

The amino acid sequences of $A X L$ of various species were obtained NCBI: Amino sequence of $A X L$ was obtained with cow (XP_010813281.1), human (NP_068713.2), horse (XP_005596 313.1), wild horse (XP_008535825.1), mouse (NP_033491.2), rat (NP_113982.1), dog (XP_005616939.1), frog (NP_001090 657.1), chicken (NP_989958.1). Amino acids were aligned using Multiple Sequence Comparison by Log-Expectation (MUSCLE) (http://www.ebi.ac.uk/Tools/msa/muscle/). Phylogenetic analysis was performed using Neighbor-Joining method [17] with pairwise deletion, 1,000 bootstrap replication, and Kimura 2 as described previously [18].

\section{Homology modelling of AXL protein}

The 3D structure of AXL was predicted by web-based homology modeling server such as Raptor X [19] and ModWeb [20]. Briefly, The templates used for modeling of immunoglobulin domain (pdb ID:2C5D), fibronectin type 3 domain (pdb ID:4PBX) and protein tyrosine kinase domain (pdb ID:3QUP) was found from RCSB protein data bank [21] based on high sequences homology and designed individually. Exceptional loop regions and C-terminus regions with no templates due to very low sequence homology were designed by ab initio calculation under CHARMM force field [22]. Connecting each domains designed independently, the initial 3D model was designed by Discovery Studio 2.5 modeling program (Studio 2009). Then a completed 3D structure was finalized by loop refinement and energy minimization under CHARMM force field [22]. The completed 3D structure was visualized by Discovery Studio Visualizer (Visualizer 2013).

\section{Statistical analysis}

Both T-test and analysis of variance statistical test was conducted to determine significance levels. Data were shown by mean \pm standard error of mean.

\section{RESULTS AND DISCUSSION}

The horse $A X L$ gene has 21 exons and 20 introns spanning about $29.91 \mathrm{~kb}$ on the chromosome 10 , and seven transcriptional variants had been predicted in NCBI gene database. The genomic structure of horse $A X L a$ and $A X L b$ (with skipping of exon 11) was shown in Figure 1A. AXLa and $A X L b$ transcript consists of 20 and 19 exons, respectively (Figure 1A) and the full lengths of the AXLa and $A X L b$ transcripts are 3,213 and 3,186 bp, respectively. Length of deleted exon 11 occurred by alternative splicing is $27 \mathrm{bp}$ (Figure 1B). Subsequently, the horse $A X L a$ transcript encodes 889 amino acids whereas $A X L b$ transcript encodes 878 amino acids. To investigate the evolutionary relationships of equine $A X L$ gene, we obtained gene sequences from eight species of

(A)

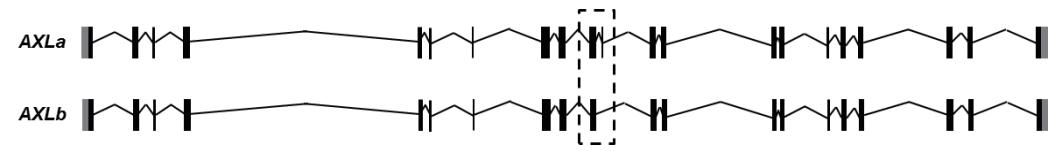

(B)

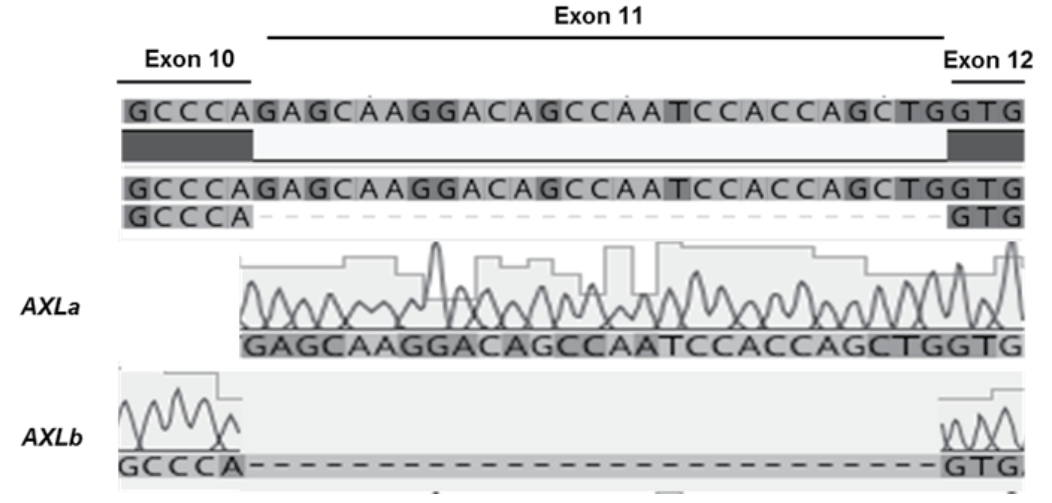

Figure 1. Alternative splicing isoforms of equine $A X L$ receptor tyrosine kinase $(A X L)$ gene. (A) Genomic structure of $A X L$ alternative splicing variants. Equine $A X L$ gene has 20 exons and two major alternative splicing forms; $A X L a$ as long form and $A X L b$ as short form. $A X L b$ has cassette exon 11 by alternative splicing. Cassette exon is marked by dashed box (B) Sequencing of alternative splicing region. Reverse-transcription polymerase chain reaction (RT-PCR) products were sequenced and confirmed that exon 11 was deleted in AXLb by alternative splicing. 
vertebrata (human, cow, dog, horse, wild horse, rat, chicken, frog, and mouse) from Ensembl 62 and conducted a phylogenetic analysis (Figure 2A). When the amino acid sequences of AXL in various species, fibronectin type 3 (FN3) domain in AXL showed higher identity (solid box in Figure 2B), and the alternative splicing was observed between exon 10 and exon 12 (with skipping

(A)

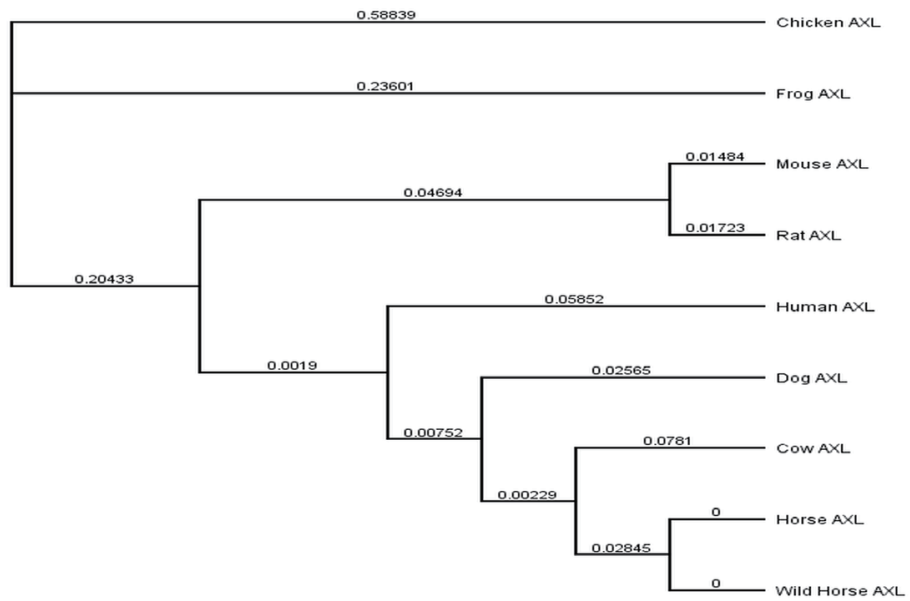

(B)

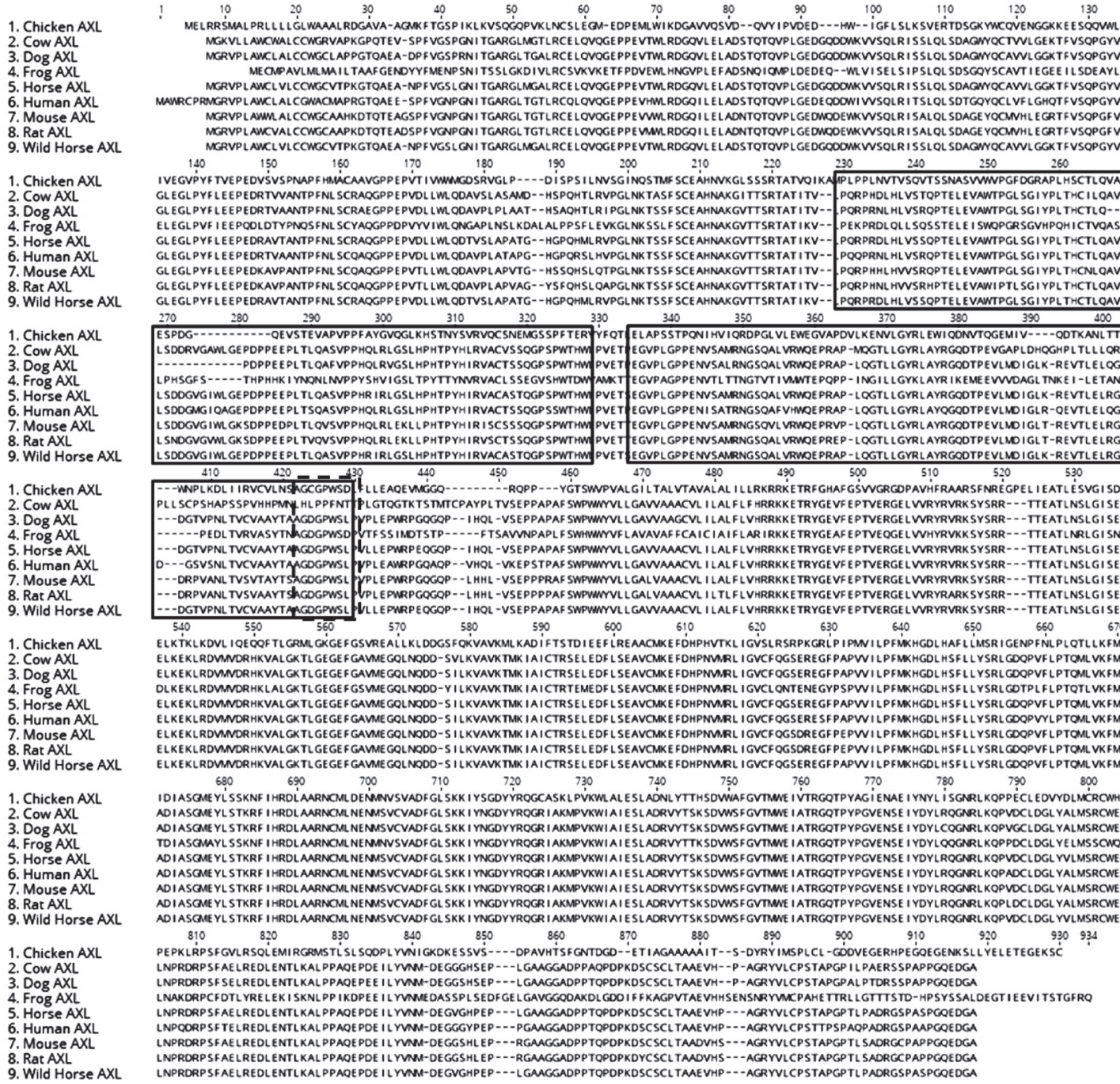

Figure 2. Analysis of amino acid sequences and phylogenetic tree of AXL receptor tyrosine kinase (AXL) gene among various species. (A) Alignments of fibronectin type 3 (FN3) domain of AXL from various species. The sequences were aligned by the MUSCLE method in GENEIOUS program. The FN3 domain is marked by solid box and the sequences deleted by alternative splicing are marked by dashed box. (B) Phylogenetic tree of AXL. The phylogenetic tree was made with the full amino acid sequences of each species by NeighborJoining method after aligned by the MUSCLE method in GENEIOUS program. Horse AXL was similar to cow and dog than frog and chicken. 
of exon 11) (dashed box in Figure 2B). Based on the phylogenetic analysis, horse AXL was evolutionarily closer to cow AXL while largely divergent from frog (Figure 2A).

Our previous study identified uniquely expressed alternative splicing forms of $A X L$ transcripts. Basically, both of alternative splicing forms were found in Ensembl (ENSECAT00000012479 and ENSECAT00000012482) data base. To detect the alternative $A X L$ transcripts, in this study, the specific primer sets were designed (Figure 3A). For AXLa transcript, the forward and reverse primers were positioned at exon 10-11 and exon 12 , respectively
(Figure 3A). Similarly, for $A X L b$ transcript, the forward and reverse primers were positioned at exon 10-12 and exon 12 , respectively (Figure 3A).

For cloning the alternative transcripts, two transcriptional variants were amplified by RT-PCR with horse skeletal muscle tissue (Figure 3B). Additionally, qRT-PCR was conducted to examine their expression patterns in horse skeletal muscle before and after exercise (Figure 3C). As a result, the expression patterns of $A X L a$ and $A X L b$ transcript in skeletal muscle revealed that the expression levels of both $A X L a$ and $A X L b$ were up-regulated

(A)

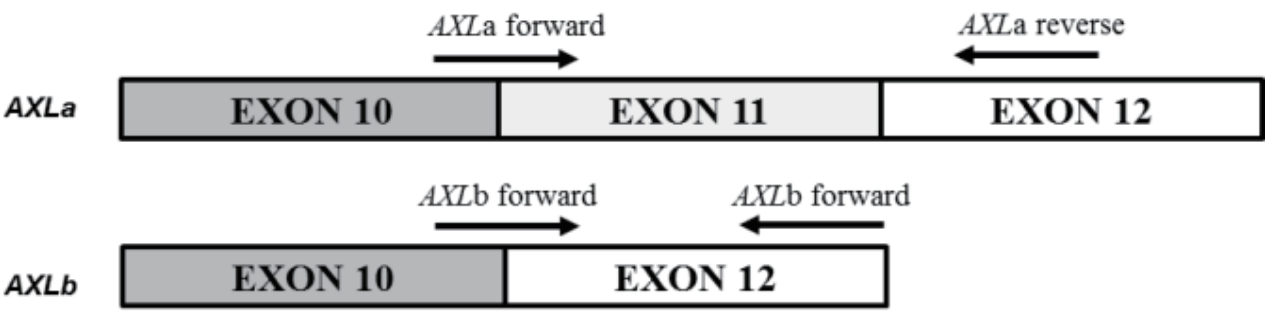

(B)
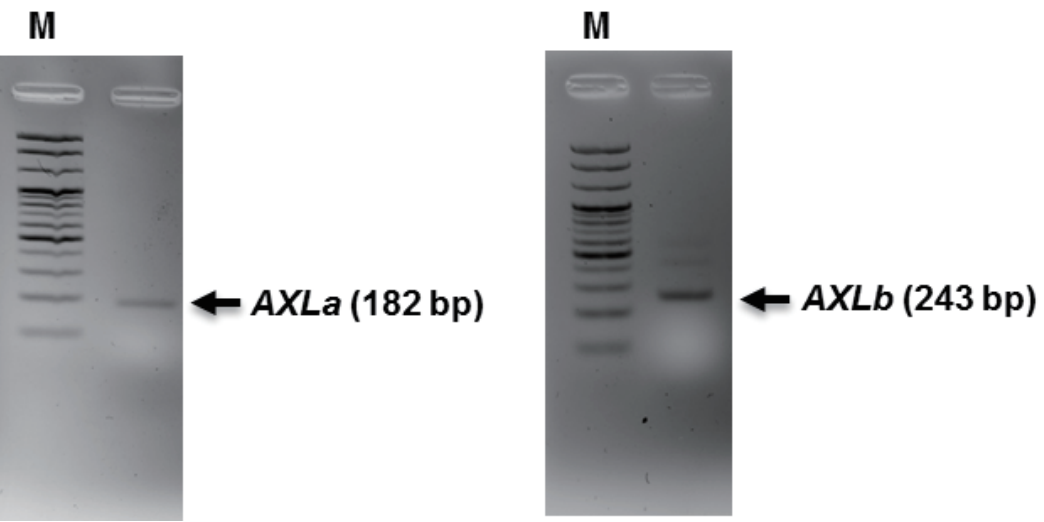

(C)
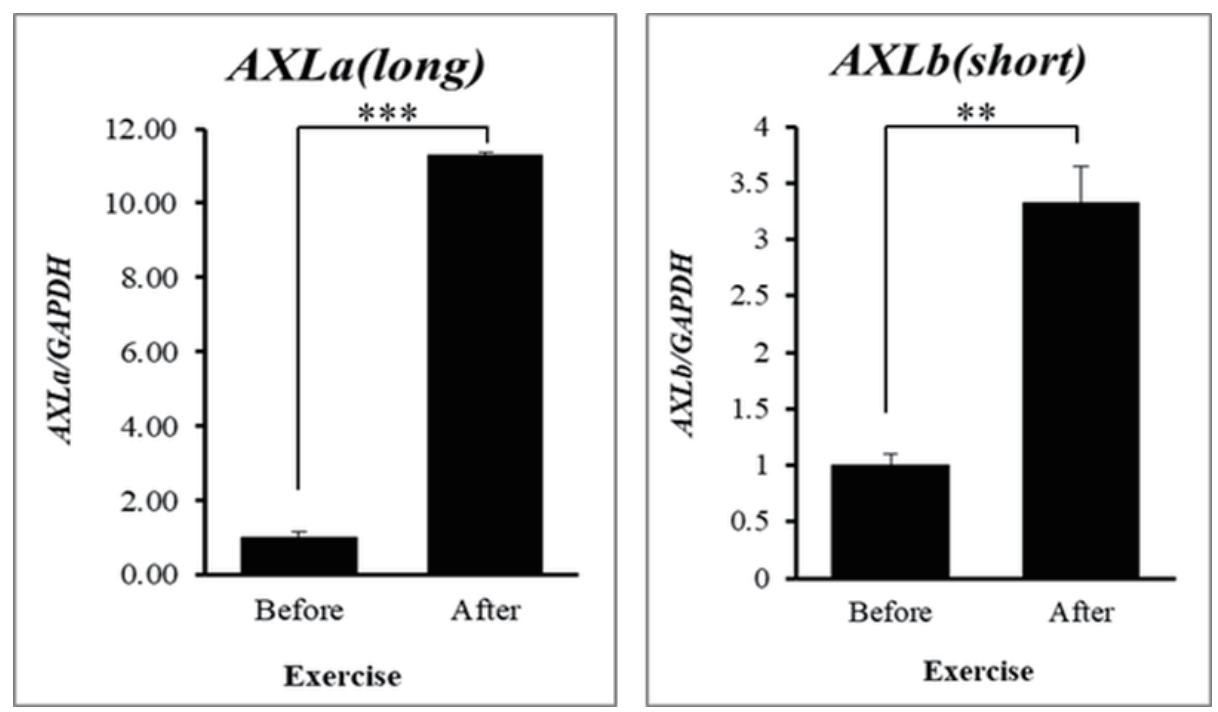

Figure 3. Expression pattern of equine $A X L$ receptor tyrosine kinase $(A X L)$ alternative splicing variants. (A) Primer designs for alternative splicing variants; $A X L a$ and $A X L b$. For $A X L a$ transcript, the forward and reverse primers were positioned at exon 10-11 and exon 12, respectively. (B) Confirmation of $A X L$ alternative splicing variants. The alternative splicing variants of $A X L$ gene, $A X L a$ and $A X L b$, were amplified by RT-PCR. (C) Relative expression of $A X L$ alternative splicing variants was analyzed by quantitative reverse-transcription polymerase chain reaction (qRT-PCR) in skeletal muscle before and after exercise. ( $n=3$, the ${ }^{* *}$ means $p<0.05,{ }^{* * *}$ means $p<0.005$ ). Quantitative analysis was performed using the $2^{-\Delta \Delta \mathrm{Ct}}$ method. Glyceraldehyde-3-phosphate dehydrogenase (GAPDH) was used for normalization. 
after exercise compared to those before exercise (Figure 3C). The transcript level of $A X L a$ after exercise was about 11-fold higher than that before exercise in skeletal muscle (Figure $3 \mathrm{C}$ left panel, $\mathrm{p}<0.005)$, and the transcript level of $A X L b$ also increased in response to exercise (Figure $3 \mathrm{C}$ right panel, $\mathrm{p}<0.05$ ).

According to a recent genome-wide association study, mouse AXL is associated with cellular transformation such as proliferation, cell survival, and angiogenesis through Gas6-AXL signaling pathway [23]. In addition, AXL is involved in stimulation of antiapoptosis through NF- $\kappa B$ signaling pathway [24]. These studies suggested that AXL may play an important role in wound healing and anti-apoptosis to damaged cells during exercise, especially in the vascular cell and skeletal muscle. Generally, acute exercise stimulates NF- $\mathrm{kB}$ signaling pathway in skeletal muscle during muscular contraction, presumably due to increased oxidant production [25]. Suggesting the importance of relationship between apoptosis and exercise, it is reasonable that regulation of $A X L$ expression maybe has important role for regulating anti-apoptosis and wound healing after exercise through NF- $\mathrm{kB}$ signaling pathway in skeletal muscle. Collectively, the results suggest that $A X L$ can be worth as marker for athletic abilities, and also for exerciserecovery after exercise

To investigate the protein structural difference between AXL alternative splicing variants, we predicted 3D structures of AXLa and AXLb with 9 amino acid deletion of exon 11 (Figure 4A). As a result of 3D structural analysis, AXLb of 9 amino acid deletion isoform showed structural differences in the regions between $\mathrm{C}$-terminus of fibronectin type 3 domain and $\mathrm{N}$-terminus of transmembrane helices compared to that of full-length AXLa isoform (Figure 4B). This structural differences may be explained by 9 amino acid deletion. However, our prediction was based on only in silico homology. Further experimental crystal structure study should be necessary to explain this AXL alternative splicing effects. Generally, dynamic kinetics and biological function of a specific signaling pathway could be changed depending on interaction between receptor and its ligand as well as their domain folding structure [26]. Therefore, the different 3D structures of the alternative AXL isoforms may be related to regulatory mechanism of signaling cascade.

\section{CONFLICT OF INTEREST}

We certify that there is no conflict of interest with any financial organization regarding the material discussed in the manuscript.

\section{ACKNOWLEDGMENTS}

This work was supported by a grant from the Next-Generation BioGreen 21 Program (No. PJ01104401, PJ01117301), Rural Development Administration, Republic of Korea.

$$
390 \quad 400 \quad 410 \quad 420 \quad 430 \quad 440
$$

AXLa GTVPNLTVCVAAYTAAGDGPWSLPVLLEPWRPEQGQPI HQLVSEPPAPAFSWPWWYVLLGA

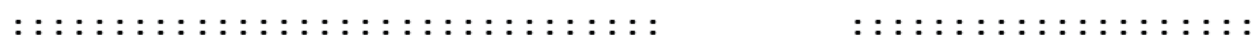

AXLb GTVPNLTVCVAAYTAAGDGPWSLPVLLEPWRP---------VSEPPAPAFSWPWWYVLLGA

(B)

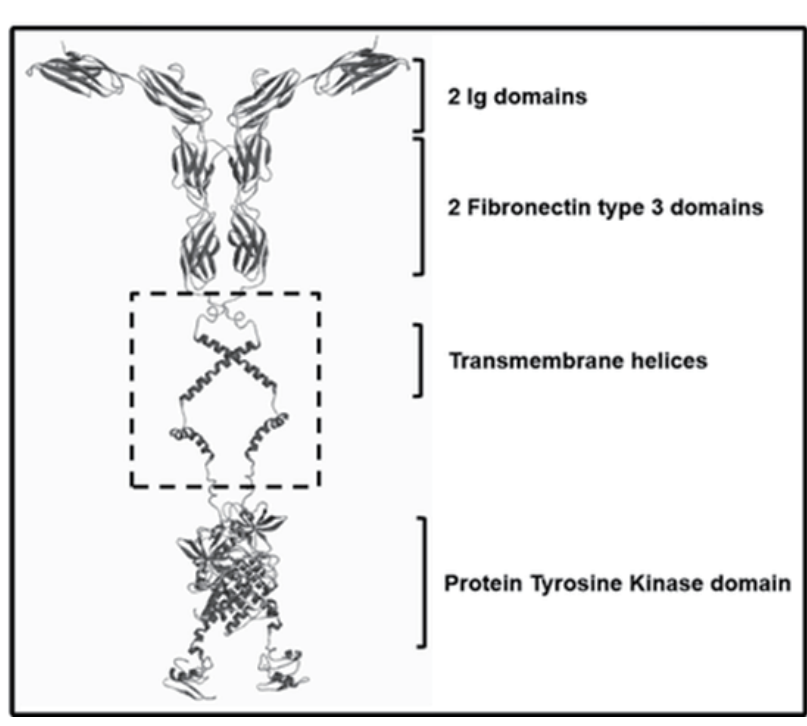

$A X L b$

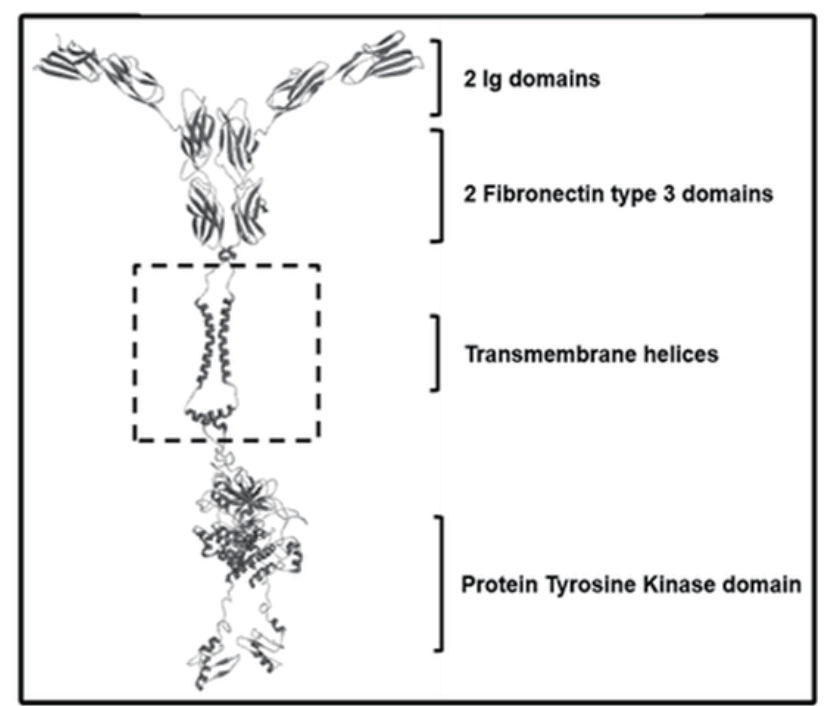

Figure 4. The comparison of amino acid sequences and protein structure between AXLa and AXLb proteins. (A) The amino sequences of $A X L a$ and $A X L b$ protein were aligned. (B) 3-dimentional (3D) structural analysis between the alternative variants. 3D prediction of the alternative protein structures revealed that the structural distance of the connective region between fibronectin type 3 (FN3) and immunoglobin (Ig) domain was different between two alternative isoforms (dashed boxes). 


\section{REFERENCES}

1. Gu J, Orr N, Park SD, et al. A genome scan for positive selection in thoroughbred horses. PloSOne 2009;4:e5767.

2. Park KD, Park J, Ko J, et al. Whole transcriptome analyses of six thoroughbred horses before and after exercise using RNA-Seq. BMC Genomics 2012;13:473.

3. O'Bryan JP, Frye RA, Cogswell PC, et al. AXL, a transforming gene isolated from primary human myeloid leukemia cells, encodes a novel receptor tyrosine kinase. Mol Cell Biol 1991;11:5016-31.

4. Sainaghi PP, Castello L, Bergamasco L, et al. Gas6 induces proliferation in prostate carcinoma cell lines expressing the AXLreceptor. J Cell Physiol 2005;204:36-44.

5. McCloskey P, Fridell YW, Attar E, et al. GAS6 mediates adhesion of cells expressing the receptor tyrosine kinase AXL. J Biol Chem 1997; 272:23285-91.

6. Tai KY, Shieh YS, Lee CS, Shiah SG, Wu CW. AXL promotes cell invasion by inducing MMP-9 activity through activation of NF- $\kappa B$ and Brg-1. Oncogene 2008;27:4044-55.

7. Cunningham BA, Hemperly JJ, Murray BA, et al. Neural cell adhesion molecule: structure, immunoglobulin-like domains, cell surface modulation, and alternative RNA splicing. Science 1987;236:799-807.

8. Fischer EH, Charbonneau H, Tonks NK. Protein tyrosine phosphatases: a diverse family of intracellular and transmembrane enzymes. Science 1991;253:401-7.

9. Varnum BC, Young C, Elliott G, et al. AXL receptor tyrosine kinase stimulated by the vitamin K-dependent protein encoded by growtharrest-specific gene 6. Nature 1995;373:623.

10. Stitt TN, Conn G, Goret M, et al. The anticoagulation factor protein $\mathrm{S}$ and its relative, Gas6, are ligands for the Tyro 3/Axl family of receptor tyrosine kinases. Cell 1995;80:661-70.

11. Sasaki T, Knyazev PG, Clout NJ, et al. Structural basis for Gas6-Axl signalling. EMBO J 2006;25:80-7.

12. Goruppi S, Ruaro E, Varnum B, Schneider C. Requirement of phosphatidylinositol 3-kinase-dependent pathway and Src for Gas6-Axl mitogenic and survival activities in NIH 3T3 fibroblasts. Mol Cell Biol 1997; 17:4442-53.

13. Hasanbasic I, Cuerquis J, Varnum B, Blostein MD. Intracellular signaling pathways involved in Gas6-Axl-mediated survival of endothelial cells.
Am J Physiol-Heart C 2004;287:H1207-13.

14. Paccez JD, Vogelsang M, Parker MI, Zerbini LF. The receptor tyrosine kinase AXL in cancer: biological functions and therapeutic implications. Int J Cancer 2014;134:1024-33.

15. Rankin EB, Fuh KC, Castellini L, et al. Direct regulation of GAS6/AXL signaling by HIF promotes renal metastasis through SRC and MET. Proc Natl Acad Sci USA 2014;111:13373-8.

16. Livak KJ, Schmittgen TD. Analysis of relative gene expression data using real-time quantitative PCR and the $2^{-\triangle \Delta C T}$ method. Methods 2001;25:402-8.

17. Saitou N, Nei M. The neighbor-joining method: a new method for reconstructing phylogenetic trees. Mol Biol Evol 1987;4:406-25.

18 Cho HW, Shin S, Park JW, et al. Molecular characterization and expression analysis of the peroxisome proliferator activated receptor delta (PPAR $\delta$ ) gene before and after exercise in horse. Asian-Australas J Anim 2015;28:697-702.

19. Källberg M, Wang H, Wang S, et al. Template-based protein structure modeling using the RaptorX web server. Nat Protoc 2012;7:1511-22.

20. Madhusudhan MS, Marti-Renom MA, Eswar N, et al. Comparative protein structure modeling. The Proteomics Protocols Handbook, Totowa, NJ: Humana Press; 2005. pp. 831-60.

21. Rose PW, Beran B, Bi C, et al. The RCSB protein data bank: redesigned web site and web services. Nucleic Acids Res 2011;39(Suppl 1):D392D401.

22. MacKerell AD, Banavali N, Foloppe N. Development and current status of the CHARMM force field for nucleic acids. Biopolymers 2000;56:257-65.

23. Holland SJ, Powell MJ, Franci C, et al. Multiple roles for the receptor tyrosine kinase axl in tumor formation. Cancer Res 2005;65:9294-303.

24. Hasanbasic I, Cuerquis J, Varnum B, Blostein MD. Intracellular signaling pathways involved in Gas6-AXL-mediated survival of endothelial cells. Am J Physiol-Heart C, 2004;287:H1207-H13.

25. Ji LL, Gomez-Cabrera MC, Steinhafel N, Vina J. Acute exercise activates nuclear factor (NF)- $\mathrm{B}$ signaling pathway in rat skeletal muscle. FASEB J 2004;18:1499-506.

26. Llinás, M. Metal-polypeptide interactions: The conformational state of iron proteins. In: Metal Bonding in Proteins. Berlin, Heidelberg: Springer; 1973. p. 135-220. 